\title{
RELATO DE UMA EXPERIÊNCIA JUNTO AO ACERVO DE MURILO RUBIÃO
}

\section{VERA LÚCIA ANDRADE}

Trabalhou durante 25 anos

na UFMG. Atualmente

é professora titular do

Instituto Superior de Ensino

Anísio Teixeira/ Fundação

Helena Antipoff. Doutora pela Université de Paris 3 (1985). Autora de variados artigos, capítulos de livros, tendo sido responsável pela

edição de Contos reunidos de Murilo Rubião (São Paulo:

Ática, 1997). Orientadora de pesquisas de mestrado e doutorado sobre Murilo Rubião e sua obra.
Tendo em vista o que me foi proposto fazer, é quase como a de um "documento histórico", enquanto primeiríssima pesquisadora, que fui, do acervo de Murilo Rubião, fato que muito me honra.

Na verdade, estive presente no acervo do Murilo, desde o seu início, desde sua inauguração, tendo sido também, em parte, responsável pelo fato de o acervo do autor ter sido doado à UFMG. Explico-me melhor: em 1989, fui convidada por Cida Falabella, produtora e diretora de teatro daqui de Belo Horizonte, a participar da preparação de uma peça que ela queria encenar, baseada na obra de Murilo Rubião. Fui convocada, assim, a ministrar um curso do qual participaram ela e todos os seus atores. Só posso dizer que foi uma experiência singular, única na minha carreira acadêmica, e que me proporcionou uma vivência prazerosa e enriquecedora. A peça se chamou "A Casa do Girassol Vermelho" e nela foram encenados três contos de Murilo, "Os três nomes de Godofredo", "A lua" e "Bárbara". No dia de sua estreia, que ocorreu no antigo Teatro Francisco Nunes, encontrei-me, na entrada, com o próprio autor dos contos, que aguardava, pacientemente, a abertura dos portões do teatro. Conversamos bastante, ele e eu, e, a certa altura, falei-lhe que havíamos recebido, na UFMG, o acervo de Henriqueta Lisboa, doado por sua sobrinha. Imediatamente, ouvi de sua boca o desejo de também ele nos doar o seu acervo, pela certeza de que ali ele seria 
utilizado para pesquisa, e teria a divulgação com que ele, Murilo, sempre sonhara. Estava ali "firmado", de certa forma, o pacto entre Murilo Rubião e a UFMG, o qual se concretizou, dois anos depois, logo após a morte de Murilo, em 20 de setembro de 1991. Portanto, como dito inicialmente, tive uma pequena participação nesta doação do acervo de Murilo, mesmo que circunstancial... Mas a efetivação real da doação do acervo do escritor deu-se pela ação de sua herdeira e sobrinha, Sílvia Rubião, que atendeu a um pedido explícito de seu tio. Até hoje, Sílvia Rubião é gestora de todo o acervo de Murilo Rubião, sendo muito atuante neste trabalho de divulgação e valorização de sua obra.

A partir de agosto de 1991, O Centro de Estudos Literários da Faculdade de Letras da UFMG passou a desenvolver o projeto "Acervos de Escritores Mineiros". Tratava-se de um projeto integrado, financiado pelo $\mathrm{CNPq}$, contando com uma equipe de professores/pesquisadores, vários bolsistas de Iniciação Científica e de Apoio Técnico, e coordenado pelo Prof. Dr. Wander Melo Miranda. Fui integrante desta equipe durante muitos anos, de 1992 a 2001, tendo acompanhado toda a fase de catalogação e sistematização do material contido no acervo de Murilo, composto por biblioteca, hemeroteca, documentos, correspondência, inéditos, fotografia, memorabilia, objetos de arte e de outros objetos pessoais do autor. Tal experiência, é claro, levou-me a conhecer mais de perto a vida e a obra do autor, fornecendome amplo material para a elaboração de vários artigos, tais como "A biblioteca fantástica de Murilo Rubião", "A trajetória fantástica de Murilo Rubião", "O leitor na biblioteca", "O feiticeiro da palavra", "Murilo Rubião: o mágico de Minas", " Murilo Rubião e os anos 40", "Murilo 
Rubião e a Geração Suplemento", dentre outros, quase todos eles apresentados e discutidos em congressos e encontros de literatura brasileira e/ou de literatura comparada, como também a organização do volume Contos Reunidos de Murilo Rubião, publicado pela Editora Ática (que foi a grande editora de Murilo, e que publicou, praticamente, todos os seus livros), em 1998. A meu ver, essa foi a minha maior contribuição para o estudo da obra de Murilo. Tal edição conta com 32 contos publicados em vida pelo autor e um inédito, "A Diáspora". Foi quando estudei as várias versões de todos os contos publicados por Murilo e fiz o estabelecimento do seu texto definitivo, optando por escolher sempre a última versão publicada em livro, exceção feita ao conto "Ofélia, meu cachimbo e o mar", que foi retirada do Suplemento Literário de Minas Gerais, no 1062, de 1987, uma edição especial dedicada a Murilo, que apresenta modificações muito significativas em relação à última edição do conto em livro, de 1982.

Um fato bastante pitoresco envolve a realização deste conto, escrito nos anos 70, ou, para ser mais fiel ao processo de criação do autor, "pronto para publicação" nos anos 70. Certo dia, quando voltava do trabalho, no centro de Belo Horizonte, para a sua casa, no bairro da Serra, Murilo esqueceu num táxi os originais de "A Diáspora". Aflito, ele divulgou amplamente o fato na imprensa local, com o objetivo de recuperar o valioso manuscrito perdido. A história ganhou as manchetes locais e contribuiu para ampliar ainda mais o já extenso folclore que cerca não somente a sua figura, por si só fantástica, como a própria feitura de seus textos. Todo esforço foi em vão, pois Murilo jamais conseguiu reaver a sua "Diáspora". Inconformado, pôs-se a reescrever o conto, 
gastando nessa tarefa, como de costume, vários anos. Nos meses que antecederam sua morte, em 1991, Murilo anunciou, por mais de uma vez, a publicação desta nova versão do conto perdido, o que não chegou a acontecer. Como foi dito, ele só veio a ser publicado em 1998, nesta antologia dos Contos Reunidos.

Quanto aos demais textos dessa antologia, aqueles 32 contos publicados pelo autor, ao longo de sua vida um outro fato curioso vai marcá-los. Aparentemente senhor de uma obra vasta, Murilo, na verdade, só escreveu três livros. Isso porque, de fato, apenas $O$ ExMágico, A Estrela Vermelha e O Convidado contêm contos totalmente inéditos; os demais retomam contos publicados anteriormente, constituindo-se em nova versão. Também em Os Dragões e outros contos há quatro histórias inéditas, sendo as demais republicações.

De 1995 a 1998, dediquei-me, mais especificamente, aos textos inéditos de Murilo, encontrados em seu acervo. Acho que cabe aqui um pequeno relato de como foi o meu primeiro contato com esses textos inéditos. A primeira vez que vi o material, ele encontrava-se tal qual havia sido organizado pelo próprio autor, em pastas de arquivo com elástico, todas elas com título manuscrito à tinta no interior das quais Murilo ia guardando, de forma desordenada, os rascunhos, as anotações, variantes, acréscimos, índices, textos semi-prontos, redigidos à mão e/ou datilografados, enfim, tudo que se referia aos textos que estava escrevendo. Ao todo eram 15 pastas, todas elas portando títulos ( $A$ Guerra e as Unhas; A cidade mutilada; A Ilha e a Busca; Jove, o pistoleiro; O Guarda-costas; O contrabandista; etc. e Botão de Rosa e a Fila (agora uma adaptação para o teatro)). 
É importante ressaltar que, no segundo semestre de 1995 e no primeiro, de 1996, realizaram-se os trabalhos de conservação do acervo e a documentação dos inéditos passou por um processo de acondicionamento, o que, sem dúvida, representou uma otimização dos mesmos, pois o material, em mau estado de conservação, apresentava dificuldades de manuseio. Os textos, então, foram retirados das pastas originais e colocados em pastas suspensas. Também foi necessário, ao longo da pesquisa, estabelecer a cronologia dos textos, pois todos eles continham, no alto da página, a indicação das datas em que foram escritos.

Outro fato interessante que pude depreender destes textos e que diz respeito também ao processo de criação de Murilo, é o fato de que a trama dos contos, ou a história propriamente dita, também vai se construindo aos poucos, até chegar a um formato completo. Há casos em que a primeira versão conta apenas com um esquema, um esboço de ideias que vão se transformando e ganhando mais detalhes, à medida que o autor vai trabalhando o texto. Às vezes também, em versões posteriores, tais detalhes eram ignorados, ou melhor, novamente transformados, ganhando outra forma, de tal maneira que, em casos como o do texto "A Cidade Mutilada", por exemplo, a última versão se distancia bastante da primeira. São, no total, 62 documentos, datados de 30/11/72 (o primeiro deles) a 26/01/87 (o último deles). Foram gastos, portanto, 14 anos e 2 meses na confecção do conto, que continuou inacabado.

O tipo de papel utilizado pelo autor também era bastante diverso: papel ofício, papel de seda para carta (muito usado), papeis com timbre de órgãos públicos em que Murilo trabalhou, cartões de visita, nota fiscal de restaurantes, etc. 
Enfim, um material riquíssimo para o estudo do processo de criação do autor e para o estudo de fontes primárias, indicando inclusive que, apesar de Murilo ser muito metódico e organizado, a criação vinha-Ihe de forma desordenada e sem hora marcada.

Enfim, meu trabalho de pesquisa nesta época consistiu na seleção e transcrição dos textos, seguidas de elaboração de notas explicativas. Pretendia, na ocasião, organizar um volume para ser publicado na série "Inéditos e Esparsos", uma coleção sob a responsabilidade do CEL/FALE, que objetivava a publicação de textos inéditos ou esparsos de autores brasileiros, levandose em conta a reconsideração de critérios de valor literário e cultural dessa produção. No entanto, não me foi possível realizar tal desejo, na medida em que surgiu uma questão ética incontornável, a vontade expressa do autor de que tais textos não fossem publicados, mas para mim, no fundo ficou aquele gostinho de frustração, diante de um material tão valioso. 